\title{
Octavio Paz y Mesoamérica: un himno entre ruinas ${ }^{1}$
}

\section{Octavio Paz and Mesoamerica: A hymn among ruins}

\author{
FABIENNE BRADU \\ Universidad Nacional Autónoma de México, \\ Instituto de Investigaciones Filológicas \\ fabbra@gmail.com
}

Resumen: Los ensayos de Octavio Paz sobre Mesoamérica - una faceta poco estudiada por la crítica y mal conocida por el gran público — revelan la mirada penetrante del poeta, y no de un especialista, sobre el mundo antiguo de México, sobre su cosmogonía y sus producciones artísticas siempre ligadas a una dimensión religiosa. Pero el poeta va más allá de la antropología y del saber en sí mismo, para subrayar la persistencia de esta cosmogonía en los mexicanos de hoy y en la cual, asimismo, se encuentran los principales fundamentos de su poética. Es a través de esta constancia que hace emerger dos Méxicos distintos, como Octavio Paz interpreta los acontecimientos de 1968 y la insurrección zapatista de 1994.

\author{
Palabras Clave: \\ Octavio Paz; \\ Mesoamérica; \\ Coatlicue; \\ movimiento estudiantil del 68; \\ levantamiento zapatista.
}

KeYWORDS:

Octavio Paz;

Mesoamerica;

Coatlicue;

Student movement of 1968;

Zapatista insurrection.
AbSTRACT: Octavio Paz's essays on Mesoamerica - a facet little studied by critics and poorly known by the general public - reveal the penetrating gaze of the poet, not of a specialist, on the ancient world of Mexico, its cosmogony and artistic productions always linked to a religious dimension. But the poet goes beyond anthropology and knowledge in itself, to underline the persistence of this cosmogony in Mexicans at present and also as encountered in the main foundations of his poetics. It is through this constancy

1 Texto leído en la conferencia homónima en el marco de la Cátedra Miguel Alemán Velasco, UnAm / Sorbonne, París, 2 de octubre de 2019, Maison de l'Amérique latine. 
that two different Mexicos emerge, as Octavio Paz interprets the events of 1968 and the Zapatista insurrection of 1994.

"No se puede reducir la historia al tamaño de nuestros rencores"

Octavio Paz

El 13 de agosto de 1790, mientras ejecutaban unas obras municipales y removían el piso de la plaza Mayor de la Ciudad de México, unos trabajadores descubrieron una estatua colosal de dos metros y medio de altura, luego identificada como la Coatlicue Mayor. Pocos días después, allí mismo aparecía el conocido Calendario Azteca. El virrey Revillagigedo mandó el Calendario a Catedral y la Coatlicue a la Real y Pontificia Universidad de México, en las actuales calles de Seminario y Guatemala, frente al Templo Mayor. "Primero la arrinconaron en un patio de la Universidad — sigue informando Octavio Paz-, después estuvo en un pasillo, tras un biombo, como un objeto alternativamente de curiosidad y de bochorno" (Paz 1995: 76). Unos indígenas comenzaron a honrarla cotidianamente con ofrendas que no caían en la gracia del obispo Móxo y Francolí quien, entonces, pidió que la diosa fuese enterrada en el patio universitario. En 1803, Alexander von Humboldt, quien tenía noticia de la diosa y de su indigna sepultura, pidió que la desenterraran para documentar sus apuntes sobre el hallazgo. Las autoridades eclesiásticas no se negaron ante la petición de un extranjero pero, apenas el alemán se marchó del país, la diosa volvió a descender al inframundo que, para el caso, colindaba con los desagües de la ciudad. A la independencia de México, en 1821, el emperador Agustín de Iturbide la rescató de las tinieblas y la expuso en el patio de la Universidad como un símbolo de la libertad recobrada después de tres siglos de colonia española. Todavía faltó que Maximiliano de Habsburgo la reubi- 
cara en el Museo Público de Historia Natural, Arqueología e Historia, a un costado de Palacio Nacional, antes de que, en 1964, la diosa conociera una última mudanza al actual Museo de Antropología e Historia, donde ahora se envanece a plena luz en la sala Mexica.

"La carrera de la Coatlicue Mayor, de diosa a demonio, de demonio a monstruo y de monstruo a obra maestra — propone Octavio Paz-, ilustra los cambios de sensibilidad que hemos experimentado durante los últimos cuatrocientos años" (1995: 76). Los lances de la Coatlicue fueron, en efecto, insólitos por no decir únicos en la historia de la antropología mexicana. En las tribulaciones de la diosa que pasó del templo al museo sin perder un ápice de su escalofriante catadura, Octavio Paz cifra el sentir de muchos mexicanos y extranjeros ante los vestigios de la civilización mesoamericana: "la estatua es un objeto que, simultáneamente, nos atrae y nos repele, nos seduce y nos horroriza" (76).

La extrañeza "comienza en sorpresa y termina en interrogación" y es la primera reacción que enfatiza Octavio Paz ante los enigmas del pasado que atraen e irritan a los hombres. "En esos objetos extraños — esculturas, pinturas, relieves, santuarios - contemplamos el fondo insondable del cosmos y nos asomamos a nuestro sin fondo" (1995: 27). Se refiere, a un tiempo, a la dimensión bicéfala de lo sagrado comentada por Rudolf Otto en Lo santo (1996) —lo maravilloso y la terribilidad en una sola vislumbrey al desconcierto que produce la ignorancia del mensaje que nos quieren transmitir esas piedras que, sin embargo, avistamos con afanosa intuición. Por lo demás, la zozobra se acentúa a causa de la paradoja que conlleva toda expresión del arte mesoamericano, que Octavio Paz explica así:

La Coatlicue Mayor nos sorprende no sólo por sus dimensiones [...] sino por ser un concepto petrificado. Si el concepto es terrible - la tierra, para crear, devora - la expresión que lo manifiesta es enigmática: cada atributo de la divinidad — colmillos, lengua bífida, serpientes, cráneos, manos cortadas- está representado de una manera realista, pero el conjunto es una abstracción. La Coatlicue es, simultáneamente, una charada, un silogismo y una presencia que condensa un "misterio tremendo" (1995: 83).

Y así sucede con muchas otras expresiones del legado mesoamericano, inseparables de su dimensión religiosa. 
A lo largo de los señeros textos que escribió acerca del pasado precolombino, principalmente en los años sesenta, a veces es difícil situar con precisión desde dónde habla Octavio Paz: el "nosotros" de El laberinto de la soledad a ratos lo incluye a él en su tipificación del mexicano, pero también lo distingue del mundo indígena sin, por tanto, encasillarlo en el bando de los españoles. Un simple retrato del poeta bastaría para descartar en su fisonomía de "visigodo" las raíces indígenas que, sin embargo, su pensamiento y su poesía no dejan de reivindicar como la otra mitad de la sangre andaluza que corre por sus venas. "La querella entre hispanistas y anti-hispanistas es un capítulo de la historia intelectual de los mexicanos", escribe en su final Itinerario (Paz 1980: 24). Pero para él, la doble herencia era también un asunto sentimental: "Fui familiar de esa disputa desde mi niñez. Mi familia paterna era liberal y, además, indigenista: antiespañola por partida doble. Aunque mi madre era española, detestaba las discusiones y respondía a las diatribas con una sonrisa. Yo encontraba sublime su silencio, más contundente que un tedioso alegato" (1980: 24). A lo cual se añade el dolor de una herida que no se había cerrado desde entonces: "yo no era, claramente, un extranjero pero, por mi apariencia y otras circunstancias físicas y morales, era un sospechoso. Así, mis compañeros [de escuela] me condenaron al destierro, no fuera de mi patria sino dentro de ella" (1980: 19). La misma sospecha parece haber teñido su relación con los antropólogos y arqueólogos mexicanos, como lo veremos más adelante. Lo cierto es que su mirada alerta siempre fue la del poeta, nunca la del especialista que no quiso ser en ningún ámbito del conocimiento.

La ambigüedad frente al pasado indígena, principalmente debido al sincretismo posterior, es otra peculiaridad del mexicano que Paz señala: "Es pasmoso que un país con un pasado tan vivo, profundamente tradicional, atado a sus raíces, rico en antigüedad legendaria si pobre en historia moderna, sólo se conciba como negación de su origen" (1997a: 78). Todavía hoy, se ignora por igual dónde descansan los restos de Cuauhtémoc y dónde se encuentra la tumba de Hernán Cortés, pero localizarlos es una de las obsesiones del país: "Cuauhtémoc y Cortés están vivos en la imaginación de todos los mexicanos y no dejan de luchar secretamente en el interior de cada uno de nosotros. Negar a uno es negar al otro y negarnos a nosotros mismos. Sus sombras forman la substancia de nuestro destino" 
(Paz 1995: 98). Y por ello, en otro momento, Paz advierte con sobrada razón: "Vivimos entre el mito y la negación, deificamos a ciertos periodos, olvidamos a otros [...] Nuestra historia es un texto lleno de pasajes escritos con tinta negra y otros escritos con tinta invisible" (1995: 119). No es exagerado afirmar que los ensayos de Octavio Paz sobre el pasado remoto de México están escritos con esta tinta invisible que, sin embargo, se vuelve legible bajo el sol de su discernimiento y su sensibilidad poética. La mayor virtud de los escritos de Paz, en todos los dominios del saber que ha explorado, consiste en volver accesible la complejidad y en transmitir un conocimiento riguroso con la calidez de una conversación.

La extrañeza que percibimos ante los vestigios de la civilización mesoamericana es resultante de su radical originalidad, un rasgo esencial que Octavio Paz enfatiza con insistencia: "América fue un continente sustraído a la historia mundial durante milenios y esta inmensa soledad explica la originalidad de sus creaciones; asimismo, su más obvia y fatal limitación: el primer contacto con el exterior aniquiló a esas sociedades" (1995: 29). Hasta con la civilización andina, los contactos fueron esporádicos y discontinuos, pues, "su horizonte mental se abría no hacia el más allá geográfico sino hacia el ultramundo de lo sobrenatural" (1995: 29). Esta soledad de milenios explica el estupor de los antiguos mexicanos ante la llegada de los españoles - no tenían categorías mentales en las que encasillar a los invasores-; también conformó su concepción del movimiento circular que para ellos conllevaban el cosmos, la naturaleza, la vida humana y cualquier ritual. El Calendario azteca es, como bien dice Paz, tiempo hecho piedra, pero piedra en movimiento. En la circularidad del cosmos y la ausencia de grandes cambios durante milenios de civilización, quiero ver una remisión a la poesía de Paz. Para comenzar, en su manía de revisar constantemente sus poemas procurando perfeccionar la forma sin alterar el contenido o los sentimientos expresados, es factible reconocer la ininterrumpida cadena de nacimientos, muertes y renacimientos que los antiguos mexicanos observaban en la naturaleza y trataban de plasmar en sus obras. "En suma, hubo comienzos y recomienzos, perfeccionamiento y declinaciones, no cambios" (1995: 35), escribe Paz para caracterizar lo remoto y, añado yo, tal vez lo propio. Además, ¿cómo no pensar en los Discos visuales (1968) realizados en colaboración con el pintor Vicente 
Rojo: cuatro discos - el número clave de Mesoamérica - ponen en movimiento cuatro poemas: "Juventud", "Concorde", "Pasaje", "Aspa"? ¿Cómo no evocar el título de uno de sus ensayos: Los signos en rotación (1965) y eventualmente la lectura activa que exige el tripartito poema Blanco de 1966? La antología de poesía mexicana que editó junto con Alí Chumacero, José Emilio Pacheco y Homero Aridjis en 1988 se titula, precisamente, Poesía en movimiento. También están los poemas: "Piedra de Sol" que, tal la mítica serpiente, se muerde la cola después de 584 endecasílabos, es decir, después de haber cumplido el ciclo venusiano, contabilidad de los antiguos mesoamericanos; "Poema circulatorio (Para la desorientación general)", donde lo maravilloso canta y el hombre es cómplice del rayo; "Mariposa de obsidiana", en el que habla la diosa Itzpapálotl o Tonantzin, la madre de todos los mexicanos, y dice:

En otros tiempos cada hora nacía del vaho de mi aliento, bailaba un instante sobre la punta de mi puñal y desaparecía por la puerta resplandeciente de mi espejito. Yo era el mediodía tatuado y la medianoche desnuda, el pequeño insecto de jade que canta entre las yerbas del amanecer y el cenzontle de barro que convoca a los muertos. Me bañaba en la cascada solar, me bañaba en mí misma, anegada en mi propio resplandor. Yo era el pedernal que rasga la cerrazón nocturna y abre las puertas del chubasco (Paz 1997b: 183).

Y tantos otros poemas, versos, himnos que cantan el misterio de Mesoamérica. "El poema es un conjunto de signos que buscan un significado, un ideograma que gira sobre sí mismo y alrededor de un sol que todavía no nace", escribe Paz en las páginas finales de El arco y la lira, antes de afirmar: "En su rotación el poema emite luces que brillan y se apagan sucesivamente" (1994c: 271), como los astros en la bóveda nocturna para los antiguos mexicanos.

Recuerdo, con las palabras de Paz, el mito fundador de la civilización mesoamericana:

El mito mexicano de la creación del mundo refiere que los dioses se juntaron en Teotihuacán para crear, por quinta vez, al mundo. Dos de ellos, tras hacer penitencia, se arrojaron a la hoguera y se convirtieron en el sol y la luna. Pero no se movían, fijos en el cielo. Ante el universo paralizado y en trance de 
perecer, los demás dioses decidieron sacrificarse; así pusieron en movimiento al sol, a la luna y al universo entero. En otro momento del mismo mito, el sol desfallece; para ponerse en movimiento, necesita alimentarse con la sangre de las estrellas (Paz 1994a).

De allí la necesidad de los sacrificios humanos para mantener al cosmos en movimiento, siempre en peligro de detenerse y perecer. Una vez más, asoma la extrañeza frente a la "barbarie" del ritual que tenía, como único objeto, la solidaridad con el cosmos. Si bien Octavio Paz pide comprensión histórica ante los sacrificios humanos, por ocasión excepcional, expresa su íntimo sobresalto: "La sociedad moderna es incomparablemente más tolerante e indulgente que las del pasado — comienza observando-, pero ¿no hemos sido contemporáneos de los regímenes totalitarios, de los campos de concentración y de varias matanzas colectivas? La visión mesoamericana del mundo y del hombre me estremece. Es una visión trágica que, simultáneamente, me exalta y me anonada. No me seduce pero es imposible no admirarla" (1995: 38).

La dualidad está en la base del pensamiento mesoamericano, encarnada para los aztecas en el dios Ometéolt, cuya representación, filtrada por el ojo de Paz, ofrece una inesperada prefiguración de ciertas pinturas de Picasso. "El mundo, en su origen, es dualidad: gemelos que se enlazan o combaten, sus abrazos y separaciones engendran las cuatro direcciones del espacio, los cuatro colores, los cuatro paraísos, los cuatro dioses, los cuatro destinos $[. .$.$] Los antiguos mexicanos vivían en un mundo regido$ por la analogía, hecho de contradicciones y correspondencias" (Paz 1995: 93). Analogía, contradicciones y correspondencias que son las bases de este mundo antiguo, asimismo son los fundamentos de la poética de Octavio Paz. Basta remitirse a El arCo y la lira o a Los hijos del limo para encontrar las referencias a la poesía moderna que igualmente podrían caracterizar el pensamiento analógico de los mesoamericanos. El arte mesoamericano maravilló a Durero antes de asombrar a Baudelaire, y en él se han reconocido temperamentos tan diversos como los surrealistas y Henry Moore, comenta Octavio Paz. Si se recuerdan las correspondencias caras a Baudelaire, así como la búsqueda de los surrealistas que André Breton fijaba en el Segundo Manifiesto: "Tout porte à croire qu'il existe un certain 
point de l'esprit d'où la vie et la mort, le réel et l'imaginaire, le passé et le futur, le communicable et l'incommunicable, le haut et le bas cessent d'être perçus contradictoirement" ${ }^{2}$ (1971: 76-77), se entiende mejor lo que estos artistas pudieron compartir con los antiguos mexicanos, incluso si algunos dirán que los separa un abismo en el tiempo y el espacio. Todo el arte moderno occidental ha nacido de encuentros similares con las artes primitivas que no fueron modelos a emular sino puertas abiertas hacia el otro lado de la realidad.

"La analogía concibe al mundo como ritmo: todo se corresponde porque todo ritma y rima -explica Octavio Paz en Los hijos del limo- - La analogía no sólo es una sintaxis cósmica: también es una prosodia. Si el universo es un texto o tejido de signos, la rotación de esos signos está regida por el ritmo. El mundo es un poema; a su vez, el poema es un mundo de ritmos y símbolos. Correspondencia y analogía no son sino nombres del ritmo universal" (1990: 97). En uno de sus más brillantes textos sobre las esculturas precortesianas, aquel que se titula "Risa y penitencia" (1962), acerca de las cabecitas rientes de la cultura totonaca de El Tajín, Octavio Paz no solamente retoma los conceptos teóricos de Los hijos del limo sobre la analogía, sino que los pone en práctica en su prosa que calca las metamorfosis del antiguo cosmos. El ritmo de su escritura figura una cadena ininterrumpida de frases casi carentes de subordinadas, que excluyen de su exposición el principio de causalidad para evocar la visión cósmica de los antiguos indígenas con sus propias armas. El antropólogo Felipe Solís Olguín afirma que en este ensayo "Octavio Paz hace gala del manejo del lenguaje para acercarse rítmicamente a la risa como expresión humana por excelencia". Al tiempo que la pone en acción en su prosodia, el poeta así la define:

El oficio que desempeña entre nosotros la causalidad lo ejercía entre los mesoamericanos la analogía. La causalidad es abierta, sucesiva y prácticamente infinita: una causa produce un efecto que a su vez engendra otro... La analogía o correspondencia es cerrada y cíclica: los fenómenos giran y se repiten como

2 "Todo sugiere que hay un cierto punto del espíritu a partir del cual cesan la vida y la muerte, lo real y lo imaginario, el pasado y el futuro, lo comunicable y lo incomunicable, lo alto y lo bajo dejan de percibirse contradictoriamente" (traducción del editor). 
en un juego de espejos. Cada imagen cambia, se funde a su contraria, se desprende, forma otra imagen, se une de nuevo a otra $y$, al fin, vuelve al punto de partida. El ritmo es el agente del cambio. Las expresiones privilegiadas del cambio son, como en la poesía, la metamorfosis; como en el rito, la máscara. Los dioses son metáforas del ritmo cósmico; a cada fecha, a cada compás de la danza temporal, corresponde una máscara (1995: 121).

Metáforas, máscaras y metamorfosis bailan sin un Ovidio para cantarlas.

Las críticas de Octavio Paz a la antropología contemporánea se han expresado en distintas modalidades y tonos. La más inesperada de ellas es un breve texto titulado "La mirada anterior", en el que Paz salta cavalièrement de Henri Michaux a Carlos Castaneda, el célebre autor de Las enseñanzas de don Juan. Como en otras ocasiones en la obra de Paz, el grano de algunos temas se esconde en pajas ajenas. Primero Paz se extraña de la ausencia de nombres mexicanos entre los investigadores de la faz secreta, nocturna de México, es decir, de la magia que todavía rige la vida del país tal una reminiscencia o una permanencia del espíritu antiguo. "Nuestros antropólogos son herederos directos de los misioneros, del mismo modo que los brujos lo son de los sacerdotes prehispánicos. Como los misioneros del siglo XVI, los antropólogos mexicanos se acercan a las comunidades indígenas no tanto para conocerlas como para cambiarlas. Su actitud es inversa a la de Castaneda. Los misioneros querían extender la comunidad cristiana a los indios; nuestros antropólogos quieren integrarlos en la sociedad mexicana" (Paz 1994: 432). Quizá el juicio de Paz suene injusto o exagerado, pero encarna un dilema que la historia reciente de México, como lo veremos un poco más adelante, actualiza cada tanto: ¿Cómo aliviar la miseria y la marginación de los indios sin catequizarlos con la biblia de la modernidad y del progreso? ¿Cómo respetar sus "usos y costumbres" incluso cuando éstos violan los derechos humanos y la ética más elemental? En todo caso, en el antropólogo Carlos Castaneda vuelto aprendiz de brujo, Octavio Paz ve un intento de comprensión directa del mundo indígena, libre del "behaviorismo norteamericano y del marxismo vulgar" (1994: 432), sendas lacras del etnocentrismo que se ignora. La 
conclusión de esta breve "mirada anterior" es elocuente de la postura de Paz frente a la antropología mayoritaria: "Alguna vez Bertrand Russel dijo que 'la clase criminal está incluida en la clase hombre'. Uno podría decir: 'La clase antropólogo no está incluida en la clase poeta, salvo en algunos casos'. Uno de esos casos se Ilama Carlos Castaneda" (1994: 437).

Aquí, Paz fabrica una falsa disyuntiva entre conocimiento y poesía, que él sería el primero en desmentir. Si bien, como ya dijimos, no pretende hablar desde la autoridad del especialista sino a partir de la sensibilidad del poeta, cualquier lector se da cuenta de que sus conocimientos van mucho más allá de los de un diletante y las apostillas a sus ensayos anteriores traicionan su empeño por actualizar constantemente los descubrimientos en materia antropológica. Armado de esta doble autoridad, Octavio Paz no ha tenido miedo de desenmascarar a los especialistas que ostentan una fraudulenta máscara de antropólogos. En las páginas de la revista Vuelta (enero 1987), lanzó una polémica pública acerca de la Escuela Nacional de Antropología e Historia (ENAH). Los motivos eran claros:

Hace unos veinte años Claude Lévi-Strauss, en el curso de una conversación en París, me dijo que nuestra Escuela Nacional de Antropología era una de las mejores del mundo. Oí opiniones parecidas en labios de [Jacques] Soustelle y de otros sabios ingleses y norteamericanos. Ninguno de ellos diría hoy lo mismo. Desde 1970 el gobierno mexicano ha gastado millones y millones de pesos en la Escuela Nacional de Antropología pero los resultados han sido pobrísimos y, en ciertos campos, nulos [...] Todo el mundo sabe que la gran mayoría de los profesores y de los estudiantes malgastan su tiempo y los dineros públicos en una inútil y desenfrenada actividad ideológica y política. Las autoridades no dicen ni pío: no hay que despertar al dragón del motín y el desorden. La ideología seudo-marxista, el falso sindicalismo, la politiquería y la pasividad de las autoridades han acabado con una institución que nos enorgullecía a todos (1987: 9).

La única salida que imaginaba y proponía Paz era cerrar la ENAH y abrir otra escuela sobre nuevas bases. Por supuesto, la reacción oficial no tardó en llegar a la revista y, en la siguiente edición, se publicó una extensa, burocrática y tediosa carta del director Manuel Gándara Vázquez, que no hizo sino atizar la indignación de Paz ante el silencio de los antropólogos de la que "prefirieron callar como el dios Harpócrates, caro a sor Juana". Entre las excepciones, cabe mencionar a la antropóloga Mercedes de la 
Garza, entonces directora del Centro de Estudios Mayas del Instituto de Investigaciones Filológicas de la UNAM, quien tuvo el tino de mandar a Octavio Paz un lote de publicaciones para refutar con obras y no con palabrerías sus denuncias del gremio. "Reconozco con alegría que esos libros son una refutación parcial de mis juicios sobre los estudios mayas en México —contestó Paz-. Digo parcial porque en este campo, todavía falta mucho por hacer" (1987: 64).

A excepción de esta polémica pública, el debate entre el gremio y el poeta fue escaso y desprovisto de críticas. Al contrario, entre los pocos antropólogos que se atrevieron a comentar las tesis y las hipótesis de Paz sobre el mundo prehispánico, la actitud era más bien admirada, incluso cuando el recordatorio de que se trataba de las visiones de un poeta podía sonar como una tácita descalificación. Pusieron en entredicho algunos detalles de su dilatado fresco: "Su forma particular de conocimiento deja los pormenores de lado — advierte una agridulce Beatriz de la Fuente-. En el caso del mundo antiguo, los detalles son para el historiador, el historiador de arte y el arqueólogo" (Fuente: 2). Haciéndole eco, la ya citada Mercedes de la Garza escribe después de la muerte de Paz: "son mucho más significativos los escritos en que expresa su experiencia, que aquellos en los que glosa interpretaciones de especialistas" (Garza: 158). Interviene aquí una suerte de recelo hacia el poeta que se atreve a pisar terrenos ajenos, así como un celo a causa de las referencias de Octavio Paz a especialistas extranjeros en detrimento de los nacionales. Es palpable la condena de Mercedes de la Garza del entusiasmo de Paz hacia las autoras norteamericanas del libro The Blood of Kings, Linda Schele y Mary Ellen Miller, porque sus descubrimientos en epigrafía maya no le parecen tan nuevos ni tan espectaculares como el poeta los presenta. Si sus detractores lo llamaban el tlatoani de las letras mexicanas, los antropólogos lo adornaron con el título de tlatimini, es decir, la palabra náhuatl que, según fray Bernardino de Sahagún, significa sabio, filósofo.

Por lo general, el aplauso intelectual fue unánime y Eduardo Matos Moctezuma, incansable exhumador del Templo Mayor, hasta concluye que "resulta impresionante que estudios posteriores hacen ver que Paz tenía razón en algunos temas que trata acerca del mundo antiguo" (Matos: 18-19). También comenta, a la luz de Postdata, escrito en 1969, algo que 
nos remite a la permanencia del pasado prehispánico en la actualidad mexicana, a la manera en que los mexicanos, al igual que los chinos, los indostanos o los árabes, "arrastran en andrajos un pasado todavía vivo" (Paz 1997a: 55). Dice Octavio Paz: "A lo largo de estas páginas ha aparecido una y otra vez el tema de los dos México, el desarrollado y el subdesarrollado. Es el tema de nuestra sociedad moderna", y añade Eduardo Matos Moctezuma: "Y creo que tiene razón" (2019: 55).

\section{III}

Es conocida y reconocida la renuncia de Octavio Paz a su cargo de embajador en la India a raíz de la matanza de Tlatelolco, el 2 de octubre de 1968, que clausuró con balas y sangre las demandas de cambio por parte de los estudiantes y otros sectores del país. El poeta no veía en el movimiento estudiantil una simple extensión de los demás que cundieron en otras partes del mundo ese mismo año. El despertar de los estudiantes mexicanos no tenía como objeto una revolución sino una lista de reformas para cambiar democráticamente el sistema político desde entonces esclerotizado y corrupto. La respuesta del gobierno de Gustavo Díaz Ordaz fue brutal, cruel, anómala e imprevisible, como la define Paz en Postdata.

El gobierno regresó a períodos anteriores de la historia de México: agresión es sinónimo de regresión. Fue una repetición instintiva que asumió la forma de un ritual de expiación; las correspondencias con el pasado mexicano, especialmente con el mundo azteca, son fascinantes, sobrecogedoras y repelentes. La matanza de Tlatelolco nos revela que un pasado que creíamos enterrado está vivo e irrumpe entre nosotros. Cada vez que aparece en público, se presenta enmascarado y armado; no sabemos quién es, excepto que es destrucción y venganza. Es un pasado que no hemos sabido o no hemos podido reconocer, nombrar, desenmascarar (1997a: 253).

La segunda parte de Posdata se dedica a mostrar cómo, el 2 de octubre en la Plaza de las Tres Culturas, se mostraban simultáneamente dos caras de la Historia: la primera es la de los hechos trágicos, y la segunda, "una representación simbólica de nuestra historia subterránea o invisible [...] un acto ritual: un sacrificio" (1997a: 291). El que habla en este segundo mo- 
mento, es el poeta visionario de El laberinto de la soledad, el más discutido y discutible: "Reducir el significado a un hecho de la historia visible es negarse a la comprensión e inclusive, someterse a una suerte de mutilación espiritual" (1997a: 314). En el prólogo a la edición inglesa de La noche de Tlateloco de Elena Poniatowska, Octavio Paz precisa cómo expresaría la cara invisible de la historia subterránea: "La operación militar [contra los estudiantes] no fue una acción política únicamente sino que asumió la forma casi religiosa de un castigo de lo alto. Una venganza divina. Había que castigar ejemplarmente. Moral de Dios padre colérico" (1979: 145). Compara los sucesos de 1968 con la rebelión popular de 1692 debida a la escasez de maíz e igualmente reprimida por el poder virreinal. En ambos momentos de la historia de México, sostiene él, no existía una propuesta de sustitución del régimen si éste cayera. Carlos Monsiváis, a la par de otros participantes en el movimiento del 68, se opuso a la interpretación de Paz: "Convertir la protesta estudiantil del 68 de un acto sacrificial a uno de los más grandes agravios a los derechos humanos, ha sido una de las más importantes victorias de los sobrevivientes a esa represión" (Monsiváis ápud Domínguez Michael: 336). El mismo Octavio Paz, en una entrevista de 1993 con Julio Scherer, antiguo director del periódico Excélsior y de la revista Proceso, aceptó que sus ideas fueron criticadas con dureza por los voceros del gobierno y los intelectuales de izquierda. Sin embargo, aducía en su defensa: "Fue una interpretación arriesgada pero no insensata ni carente de fundamento. Hay una continuidad en la historia de México (como en la de todos los pueblos) y esa continuidad es secreta: está hecha de imágenes, creencias, mitos y costumbres" (Paz ápud Domínguez Michael: 337).

Paralelamente a sus críticas al gobierno y al sistema priísta, Octavio Paz no solía callar sus reclamos a la izquierda mexicana, lo cual le valió, en muchas ocasiones, ser el blanco de un repudio simultáneo de la derecha y de la izquierda. Contra viento y marea, sostenía: "En México hay un horror, que no es excesivo llamar sagrado, a todo lo que sea crítica y disidencia intelectual; una diferencia de opinión se transforma instantánea e insensiblemente en una querella personal" (1997a: 259). La incapacidad para elaborar un programa viable de reformas cinco años después del 2 de octubre de 1968 es un reproche que Octavio Paz dirigió a la sociedad 
mexicana ilustrada. El movimiento del 68 fue diezmado, encarcelado, exiliado, por la represión del gobierno, pero la crítica de Octavio Paz fue más allá del recuento de fuerzas inmediatamente posterior a la masacre de Tlateloco. "Los grupos que desean el cambio en México, escribe, deberían empezar por autodemocratizarse, es decir, por introducir la crítica y el debate dentro de sus organizaciones" (1979: 151). También cabe recordar que no ahorró sus saetas a la derecha mexicana de entonces: "En cuanto a la derecha: hace mucho que la burguesía mexicana no tiene ideas — sólo intereses" (1979: 151). Por supuesto, como se volverá una costumbre entre los intelectuales de izquierda, el resentimiento producido por las observaciones de Paz tenderá a borrar sus críticas a la derecha mexicana y a reducir sus textos a una visión unilateral —y casi obsesiva — de la realidad política y social. Posdata fue escrito al calor de los acontecimientos y con el fuego de la pasión, y sólo me gustaría subrayar una pequeña frase del libro que, a mi juicio, resume mejor que cualquier otra el pensamiento social de Octavio Paz si se la medita con detenimiento y profundidad: "[...] en mi utopía política no todos somos felices pero, al menos, todos somos responsables" (1997a: 286).

\section{IV}

Sobre esta responsabilidad de todos, volverá Octavio Paz a propósito del levantamiento zapatista, el 1 de enero de 1994. "Casi todos, en mayor o menor grado, somos culpables de la inicua situación de los indios de México pues hemos permitido, con nuestra pasividad o con nuestra indiferencia, las exacciones y los abusos de cafetaleros, ganaderos, caciques y políticos corrompidos" (1994b: C), escribe el 18 de enero de 1994 en una carta enviada al periódico La Jornada. Sus ataques van dirigidos sobre todo a los intelectuales de izquierda, nacionales y extranjeros, que se subieron al tren de la revolución en las horas siguientes al levantamiento, sin tomarse el cuidado de analizar sensatamente la situación. "Algunos se obstinan en proclamar la espontaneidad de la revuelta", advierte Paz cuestionando ahora la responsabilidad del gobierno: “¿Cómo es posible que nuestras autoridades hayan ignorado que desde hacía mucho se preparaba un movimiento militar en Chiapas? Y si lo sabían, ¿por qué no tomaron a 
tiempo las medidas del caso? El gobierno ha dado a estas preguntas una respuesta tardía y poco convincente. Su responsabilidad es grave e inocultable" (1994b: C).

Asimismo condena los medios escogidos por los mandos zapatistas para hacer oír las voces de los indios:

No cierro los ojos ante la miseria y el desamparo de las comunidades indígenas. Cambian los sistemas políticos y económicos, unos suben y otros bajan, gobiernos van y gobiernos vienen, pasan los años y los siglos, pero nadie los oye ni escucha sus quejas. La elocuente carta que el 18 de enero envió el "subcomandante" Marcos a varios diarios, aunque de una persona que ha escogido un camino que repruebo, me conmovió de verdad: no son ellos, los indios de México, sino nosotros, los que deberíamos pedir perdón (1994b: C).

He aquí el párrafo alusivo de la carta del subcomandante Marcos que desgraciadamente hoy, en 2019, con un nuevo gobierno que presume el cambio, sigue teniendo una tremenda actualidad:

¿De qué tenemos que pedir perdón? ¿De qué nos van a perdonar? ¿De no morirnos de hambre? ¿De no callarnos en nuestra miseria? ¿De no haber aceptado humildemente la gigantesca carga histórica de desprecio y abandono? ¿De habernos levantado en armas cuando encontramos todos los otros caminos cerrados? ¿De no habernos atenido al Código Penal de Chiapas, el más absurdo y represivo del que se tenga memoria? ¿De haber demostrado al resto del país y al mundo entero que la dignidad humana vive y está en sus habitantes más empobrecidos? ¿De habernos preparado bien y a conciencia antes de iniciar? ¿De haber llevado fusiles al combate, en lugar de arcos y flechas? ¿De haber aprendido a pelear antes de hacerlo? ¿De ser mexicanos todos? ¿De ser mayoritariamente indígenas? ¿De llamar al pueblo mexicano a luchar de todas las formas posibles, por lo que les pertenece? ¿De luchar por libertad, democracia y justicia? ¿De no seguir los patrones de las guerrillas anteriores? ¿De no rendirnos? ¿De no vendernos? ¿De no traicionarnos?" (EZLN: 89).

La cita es larga, pero el subcomandante Marcos, hoy reconvertido a un silencioso subcomandante Galeano, era entonces un escritor más prolífico aún que Octavio Paz.

Unas causas del levantamiento eran históricas y otras contemporáneas, aduce Octavio Paz remitiendo, una vez más, a los dos Méxicos que siguen 
coexistiendo en la historia moderna. En víspera de las negociaciones en San Cristóbal de Las Casas, Octavio Paz volvía a plantear el meollo de la pugna entre las reivindicaciones locales de los indígenas y las nacionales que competían a todos los mexicanos. El 5 de febrero de aquel aciago año electoral mancillado por el asesinato de Luis Donaldo Colosio, Paz decía en voz alta lo que muchos pretendían pasar por alto. “¿Cómo la cultura de los indios chiapanecos puede traducirse a la modernidad? ¿Y cómo esa cultura puede insertarse en la moderna cultura mexicana? El problema es inmenso; no pretendo, no digamos ya resolverlo, sino siquiera plantearlo en todos sus términos" (1994b: F). ${ }^{3}$ Un poco después, se limitaba a señalar: "El mestizaje cultural ha sido la respuesta de México a la singularidad india, lo mismo en el XVI que en la época moderna. El elemento indígena está en todos los dominios de la cultura y la vida mexicana, de la religión a la poesía, de la familia a la pintura, de la comida a la cerámica" (F).

Para no prolongar lo que, en la vida del país, se ha prolongado hasta el día de hoy, dejaré aquí los cuestionamientos de Octavio Paz y los días de prueba que se sucedieron en Chiapas y en México. Ignoro quién y cuándo se encontrará una respuesta a lo que Paz escribió con tinta demasiado visible. La vox populi asegura que el pasado indígena está resurgiendo tangiblemente en México y que prueba de ello son los monumentos coloniales que van hundiéndose en la plancha del Zócalo mientras los templos prehispánicos emergen cada vez más del asfalto. La imagen es seductora, pero también la violencia que azota el país puede verse como un retorno del dios Huitzilopochtli, la cara más terrible y temible de Mesoamérica. Las últimas palabras públicas de Paz, en ocasión de la inauguración de la Fundación Octavio Paz el 17 de diciembre de 1997, se refirieron a esto mismo: "México es un país solar. Y siendo un país donde el sol abunda, un país rico de sol, pródigo del sol, es también un país negro, un país oscuro. Esta dualidad de México me preocupó desde niño y esta preocupación me llevó, sin saberlo ni quererlo, a escribir algunas páginas de El laberinto de la soledad".

Mejor regresemos a la poesía para concluir lo inconcluso y lo insatisfecho por la vía de la política, la economía y la justicia, que han mostrado

3 El énfasis es del texto original. 
una incapacidad secular para imaginar una solución, no únicamente al desamparo de los indígenas, sino también a la riqueza de la doble sangre que corre por las venas de los mexicanos. Terminaré con un breve poema: "Hermandad", de Octavio Paz, y un fragmento del "Concurso de poetas en casa de Tecayehuatzin", poema recuperado por Ángel María Garibay; ambos resuenan en la misma noche y se corresponden en un mismo cielo.

Soy hombre: duro poco

y es enorme la noche.

Pero miro hacia arriba:

las estrellas escriben.

Sin entender comprendo:

también soy escritura

y en este mismo instante

alguien me deletrea

(Paz 2004: 112).

¿Conque he de irme, cual flores que fenecen?

¿Nada será mi nombre alguna vez?

¿Nada dejaré en pos de mí en la tierra?

¡Al menos flores, al menos cantos!

¿Cómo ha de obrar mi corazón?

¿Acaso en vano venimos a vivir, a brotar en la tierra?

(Garibay 2014: 140)

\section{Bibliografía}

BRETON, ANDré. Manifestes du surréalisme. Paris: Gallimard, 1971.

"Dejar un recuerdo", en Poesía indígena de la altiplanicie. Selección, versión, introducción y notas explicativas de Ángel María Garibay K. México: Universidad Nacional Autónoma de México, 2014. 140.

Domínguez Michael, Christopher. Octavio Paz en su siglo. México: Aguilar, 2014.

EZLN. Documentos y comunicados. $1^{\circ}$ de enero / 8 de agosto de 1994. Pról. Antonio García de León. México: Era, 2003.

Fuente, Beatriz de la. "Octavio Paz y el mundo prehispánico". Manuscrito en archivo de Beatriz de la Fuente. México: Universidad Nacional Autónoma de México. Instituto de Investigaciones Estéticas.

Garza, Mercedes de la. "Los mayas en la mirada de Octavio Paz", en Anuario de la Fundación Octavio Paz. México, 2 (2000). 
Matos Moctezuma, Eduardo. Octavio Paz y la arqueología. México: El Colegio Nacional, 2019 (Opúsculos).

OtTo, Rudolf. Lo santo. Traducción de Fernando Vela. Madrid: Alianza, 1996.

Paz Octavio. "Risa y penitencia", en Los signos en rotación y otros ensayos. Ed. Carlos Fuentes. Madrid: Alianza, 1971. 15-32.

Paz, Octavio. El ogro filantrópico. Historia y política 1971-1979. México: Joaquín Mortiz, 1979.

Paz, Octavio. Itinerario. México: Fondo de Cultura Económica, 1980.

Paz, Octavio. Los hijos del limo. Del romanticismo a la vanguardia. Barcelona: Seix Barral, 1990.

Paz Octavio. "El águila, el jaguar y la virgen. Voluntad de forma". Introducción a la exposición Esplendores de treinta siglos. México: Consejo Nacional para la Cultura y las Artes. Colegio de San Ildefonso, 1994a.

Paz, Octavio. "Chiapas, ¿nudo ciego o tabla de salvación?", en Vuelta, vol. 18, núm. 201 (febrero de 1994b). C-H.

Paz, Octavio. El arco y la lira, en Obras completas, tomo I. Barcelona / México: Círculo de Lectores / Fondo de Cultura Económica, 1994c.

Paz, Octavio. "La mirada anterior", en Excursiones / Incursiones. Dominio Extranjero. Edición del autor. México: Círculo de Lectores / Fondo de Cultura Económica, 1994d. 428-437.

Paz, Octavio. Los privilegios de la vista (II), en Obras completas, tomo 7. Barcelona / México: Círculo de Lectores / Fondo de Cultura Económica, 1995.

Paz, Octavio. El laberinto de la soledad. Postdata. Vuelta a El laberinto de la soledad. México: Fondo de Cultura Económica, 1997a (Colección Popular).

Paz, Octavio. Obra poética. 1935-1970. Barcelona / México: Círculo de Lectores / Fondo de Cultura Económica, 1997b.

Paz, Octavio. Obra poética II, t. 12 de las Obras completas. Barcelona / México: Círculo de Lectores / Fondo de Cultura Económica, 2004.

Paz, Octavio, Alfonso Medellín y Francisco Beverido. "Tres ensayos sobre antropología e historia", en Vuelta. México, núm. 122 (enero de 1987).

Solís, FELIPE. "Viajes por el arte prehispánico", en Materia y sentido. El arte mexicano en la mirada de Octavio Paz. México: Instituto Nacional de Antropología e Historia, 2009. 168-187.

FABIENNE BRADU

Doctora en Letras Romances por la Universidad de la Sorbona (Paris IV) en 1982. De 1982 a 1998, fue colaboradora de la revista Vuelta y miembro de la mesa de redacción. Traductora al francés de los siguientes poetas: María Baranda, Fabio Morábito, Pablo de Rokha, Gonzalo Rojas, Rafael Cadenas, José Luis Rivas. Y al español 
de distintos autores franceses, entre otros: Annie Le Brun, André Breton, Jean Genet, Aimé Césaire. Miembro del comité editorial de literatura del Fondo de Cultura Económica.Caballero de las Artes y Letras por la República francesa y condecorada con la insignia del Águila Azteca por el gobierno de México. Miembro del Sistema Nacional de Investigadores, nivel II; y PRIDE nivel D. 